\title{
THE AZ 5214E RESIST IN EBDW LITHOGRAPHY AND ITS USE AS A RIE ETCH-MASK IN ETCHING THIN AG LAYERS IN N 2 PLASMA
}

\author{
Robert Andok* — Anna Benčurová * Pavol Hrkút* \\ - Anna Konečníková ${ }^{*}$ — Ladislav Matay ${ }^{*}$ - Pavol Nemec ${ }^{*}$ \\ — Jaroslava Škriniarová ${ }^{* *}$
}

\begin{abstract}
In this article we describe the electron-beam direct-write (EBDW) lithography process for the AZ 5214E photoresist which is, besides its sensitivity to UV radiation, sensitive also to electrons. An adapted process flow is provided. At the same time we examine the resistance of this resist to RIE and its suitability as an etch-mask for etching thin $\mathrm{Ag}$ layers in $\mathrm{N}_{2}$ plasma. A comparison with several chosen resists (PMMA, ma-2405, ma-N 1402, SU-8 2000) is provided.
\end{abstract}

K e y w o r d s: AZ 5214E resist, PMMA resist, image reversal, EBDW lithography, characteristic curves, RIE, etch-rates

\section{INTRODUCTION}

Coming out from observations that some positive ultraviolet (UV) resists are e-beam sensitive and behave like photosensitive resists, we have fixed on one of such resist representatives, namely on the commercial AZ 5214E photoresist manufactured by Clariant Corp. (Switzerland). This resist is a mixture of solid and liquid substances ( $\sim 72 \%$; containing nominally $0.5 \%$ of water $)$. Its solid constituents are formed by a novolac (phenolformaldehyde polymer resin) and a diazonaphthoquinone (DNQ) photoactive compound; the latter blended into the novolac polymer matrix, enabling the dissolution of the novolac matrix in aqueous base solutions if irradiated or non-irradiated by UV light (resp. by electrons). The main liquid constituent in AZ 5214E is the propylene glycol monomethyl ether-1,2-acetate (PGMEA) solvent [1].

According to its Product Data Sheet, AZ 5214E shows besides its sensitivity to UV radiation, also sensitivity to irradiation by electrons. Recently several articles have been published with regard to the mentioned resist; let us mention some concerning the resist's deposition technique $[2,3,7]$, e-beam proximity effect corrections and diffusion in the photoresist [4], the resist's mechanism and evaluation [5], as planarizing and bridging material $[6,7]$, some applications [5,9], etc.

The AZ 5214E photoresist is normally intended for lift-off techniques which call for a negative wall profile. Although it is a positive photoresist comprised of a novolak resin and DNQ as photoactive compound (PAC), it is mostly used in the image reversal (IR) mode also for its excellent dry etch resistance and thermal stability. The PAC is consumed during the exposure and once fully exposed, the resist will not any longer contain unreacted PAC. The resist's IR capability is obtained by a special crosslinking agent which becomes active at temperatures above $110^{\circ} \mathrm{C}$ and only in the exposed areas of the resist [1]. The crosslinking agent together with exposed PAC lead to an almost insoluble (in developer) and no longer light sensitive substance, while the unexposed areas still behave like a normal unexposed positive photoresist. After a maskless flood exposure, the overall result is a negative image of the mask pattern with a negative wall profile ideally suited for lift-off. The principle of reversal baking with the AZ 5214E resist is well described in [5]. With variations to the basic image reversal scheme and without much increase in chemical count, one may fine-tune lithography recipes to suit particular needs. An example of how the scheme can be applied to a practical lift-off lithography can be found for instance in [9].

The AZ 5214E has been reported also as a suitable masking resist for the RIE etching [10]. For patterning of thin $\mathrm{Ag}$ (and some other metallic) layers the use of $\mathrm{H}_{2}$, $\mathrm{He}$ and Ar as etching gasses has been described in [11]. Etching of silver thin films deposited on glass using inductively coupled $\mathrm{Cl}_{2}$-based plasmas and the effects of various $\mathrm{Cl}_{2}$-based gas mixtures on the formation of reactive byproducts affecting $\mathrm{Ag}$ etching was investigated, $\mathrm{eg}$, in [12]. Using of halogen gases for the patterning of Ag layers is not suitable because for the gaseous reactive products of the etching, characterized by their boiling point (b.p.), the temperature is $1159{ }^{\circ} \mathrm{C}$ for $\mathrm{AgF}$ and up to $1550{ }^{\circ} \mathrm{C}$ for the reactive $\mathrm{AgCl}$ product, respectively. More suitable product of the etching seems to be $\mathrm{AgCO}_{3}$ which requires the temperature of only $270{ }^{\circ} \mathrm{C}$ (b.p.); however in the presence of oxygen the resist quickly degrades. The applicability of nitrogen oxide for dry etching of some metals (also Ag) and metallic alloys has been patented in [13]. The most suitable etching gas for our purpose turned out to be $\mathrm{N}_{2}$ which requires only the temperature

\footnotetext{
* Institute of Informatics, Slovak Academy of Sciences, Bratislava, Slovakia, Robert.Andok@savba.sk; ${ }^{* *}$ Institute of Electronics and Photonics, STU FEI, Bratislava, Slovakia, Jaroslava.Skriniarova@stuba.sk
} 


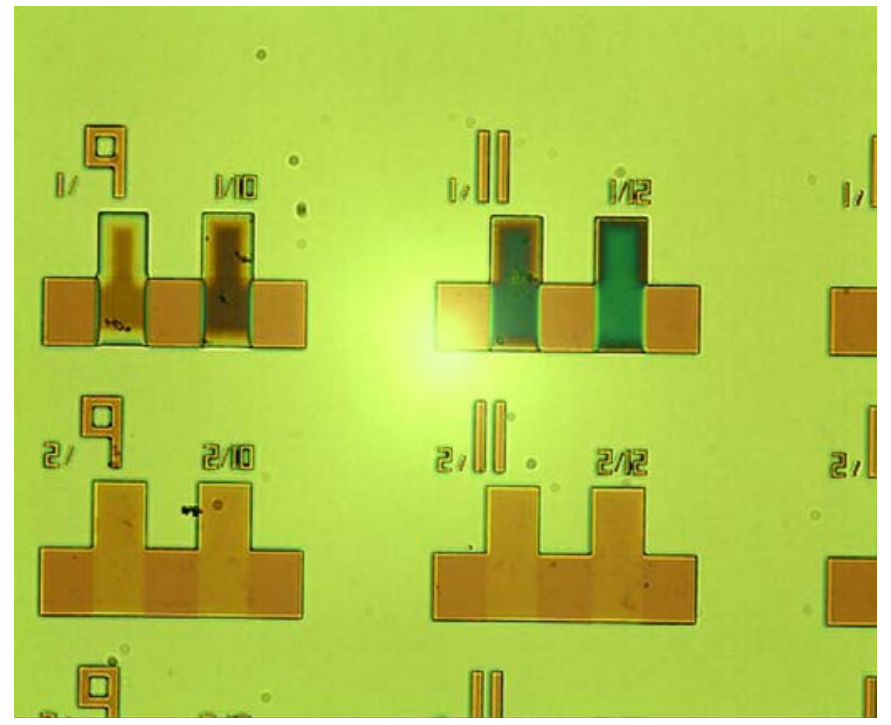

Fig. 1. Example of an EW test with under-, over- and normally-exposed areas, respectively

of $297^{\circ} \mathrm{C}$ to create an $\mathrm{AgN}_{3}$ etching product. We have supposed that during the bombardment of the surface of the silver layer by nitrogen ions (resp. by radicals that are created in nitrogen plasma), these particles would react with the $\mathrm{Ag}$ atoms on the surface of the sample and would create $\mathrm{AgN}_{3}$ products which are subsequently withdrawn by diffusion from the sample's surface.

\section{EXPERIMENTAL}

The EBDW lithography experiments have been carried out on ZBA $21(20 \mathrm{kV}$ ) and ZBA 23 (40 kV mode, $\mathrm{LaB}_{6}$ cathode) variable shaped e-beam pattern generators (Carl Zeiss, Jena; currently Vistec, Ltd.) at II SAS. We have used the so called Exposure Wedge (EW) test that serves for the construction of the sensitivity (characteristic) curve and for extracting the contrast $\gamma$ value of the resist for optimized resist pre- and post- exposure process parameters. We obtained the dependency of the remaining resist thickness to the applied exposition dose within large-area exposures (Fig. 1). We have exposed series of EW test samples (deposited on Si as well as on GaAs substrates) with exposure doses ranging from 10 to $640 \mu \mathrm{C} / \mathrm{cm}^{2}$. Our experiments showed that the AZ $5214 \mathrm{E}$ resist is electron sensitive and further in the text we show its technological process flow that suited our technological needs.

In order to obtain ca $400 \mathrm{~nm}$ film thickness at $5500 \mathrm{rpm}$ spin-speed, we used diluted solution of AZ 5214E (1:1, by the AZ EBR Solvent). We adjusted the following resist process flow for the AZ 5214E in IR mode useful for the EBDW patterning: standard resist spin-coating; prebake at $120^{\circ} \mathrm{C} / 120 \mathrm{~s}$ on hotplate (HP); EBDW lithography (ZBA23 at $40 \mathrm{kV}, 50 \mathrm{~nm}$ mode); post-bake at $115-130{ }^{\circ} \mathrm{C} / 2 \mathrm{~min}$ with a step of $5{ }^{\circ} \mathrm{C}$ (for technology fine-tuning); UV maskless exposure (Karl Süss) for $15 \mathrm{~s}$ (this step turns the resist to IR); resist development in
AZ400K $+\mathrm{H}_{2} \mathrm{O}$ (1:5) for $1 \mathrm{~min}$; final rinse in $\mathrm{H}_{2} \mathrm{O}$ for $10 \mathrm{~s}$.

Figure 2 shows normalized resist thickness dependence as a function of exposure dose for four different postbake temperatures ranging from 115 to $130^{\circ} \mathrm{C}$, step $5^{\circ} \mathrm{C}$ (for 2 min at hot-plate). Silicon wafers were used as substrates. As the most critical parameter of the IR process is the reversal-bake temperature, it was kept constant within $\pm 1{ }^{\circ} \mathrm{C}$ to maintain a consistent process [1]. This temperature was optimised individually. Finally we considered $125^{\circ} \mathrm{C}$ to be the optimal post-bake temperature for our process, which is in good agreement with the results indicated in [5]. The measurements on EW tests were carried out using the standard profilometry technique (Talystep, Alphastep).

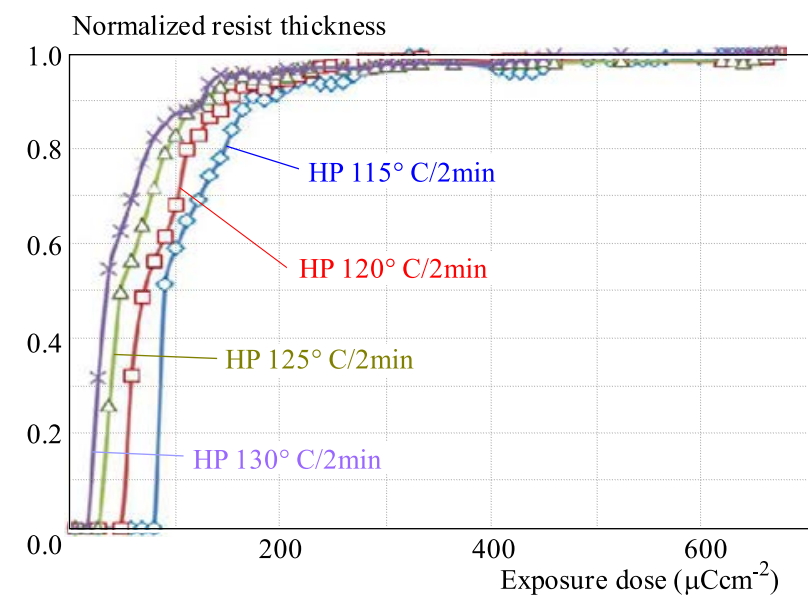

Fig. 2. Characteristic curves for the AZ 5214E resist (in IR mode) on $\mathrm{Si}$ at $40 \mathrm{kV}$ accelerating voltage

For the RIE experiments, Ag layers of $48 \mathrm{~nm}$ thickness were evaporated on Si wafers using EB PVD technique. The masking resist layers were spin-coated and patterned 
Table 1. RIE parameters for $\mathrm{N}_{2}$ plasma of selected resists

\begin{tabular}{ccccccc}
\hline Resist type & $\begin{array}{c}\text { RF } \\
\text { power } \\
(\mathrm{W})\end{array}$ & $\begin{array}{c}\text { etch time } \\
(\mathrm{min})\end{array}$ & $\begin{array}{c}\text { Intitial resist } \\
\text { thickness } \\
(\mathrm{nm})\end{array}$ & $\begin{array}{c}\text { Resist thickness } \\
\text { after the etching } \\
(\mathrm{nm})\end{array}$ & $\begin{array}{c}\text { etch rate } \\
(\mathrm{nm})\end{array}$ & $\begin{array}{c}\text { (ER) } \\
(\mathrm{nm} / \mathrm{min})\end{array}$ \\
\hline PMMA & 500 & 1.5 & 1000 & 90 & 910 & 607 \\
PMMA & 300 & 3 & 1000 & 400 & 600 & 200 \\
PMMA & 100 & 0.7 & 371 & 339 & 32 & 48 \\
ma-N 1402 & 500 & 5 & 1900 & 1372 & 528 & 105 \\
ma-N 2405 & 500 & 5 & 900 & 465 & 435 & 87 \\
AZ 5214 E & 500 & 5 & 1300 & 945 & 355 & 71 \\
$\begin{array}{c}\text { AZ5214 E } \\
\text { (mod. }\end{array}$ & 500 & 5 & 1100 & 791 & 309 & 62 \\
for IR) & & & & & & \\
SU-8 & 500 & 5 & 450 & 138 & 212 & 42 \\
\hline
\end{tabular}

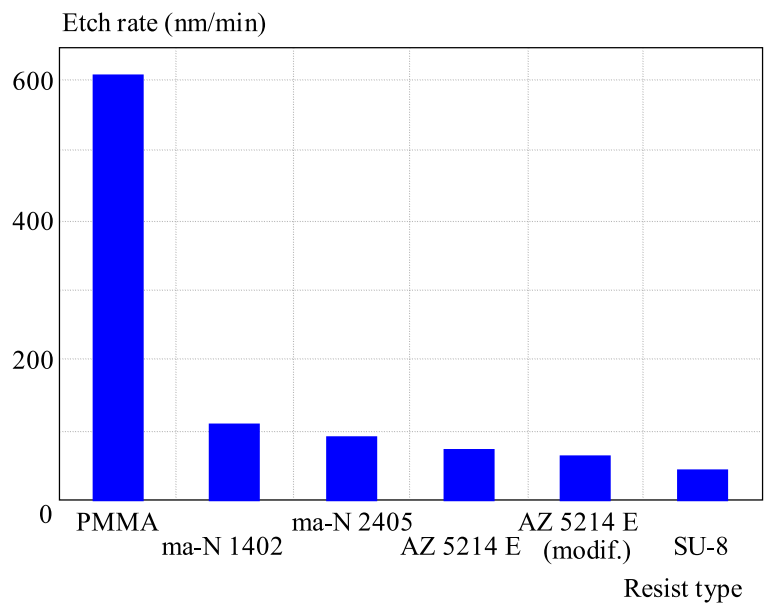

Fig. 3. Etch rates of selected resists in $\mathrm{N}_{2}$ plasma

by the EBDW lithography on the ZBA 21 (20 keV) variable shaped e-beam pattern generator. In order to check the etching process in $N_{2}$ plasma, a part of the samples containing Ag was covered with a layer of various resists. The samples were dried on a hot-plate and RIE etched in SCM 600 ( $1 \mathrm{~Pa} ; 20 \mathrm{sccm} ; 500 \mathrm{~W})$. After 8 minutes the non-masked Ag layer was completely etched away, what testified the suitability of $\mathrm{N}_{2}$ as an etching gas. Also the etch time of 4 minutes showed to be sufficient for etching through the $\mathrm{Ag}$ layer. In order to optimize the etching process it was necessary to estimate the etch-rate (E.R.) of the resist layers and of the silver layer. The etch-rates of selected resists are shown in Fig. 3.

The following resists were etched in $\mathrm{N}_{2}$ plasma: PMMA (mol. weight 450 000), ma-2405, ma-N 1402 ( $M i$ cro Resist Technology, Berlin, Germany), AZ 5214 E (MicroChemicals, Ulm, Germany; also used in IR mode), and SU-8 2000 (MicroChem Corp.), respectively. The parameters of plasma etching (with $p=1 \mathrm{~Pa}, \mathrm{RF}$ in the range $\left.100-500 \mathrm{~W}, U_{S B}=-300 \mathrm{~V}\right)$ are summarized in more details in Table 1 .

As can be seen in Fig. 1, from the examined resists, the highest E.R. in $\mathrm{N}_{2}$ plasma was found for the PMMA resist and the lowest E.R. was obtained for the SU-8 resist (the value only slightly less than that of AZ 5214E). During the lithography processing of the ma-N 1420 resist we have observed that the used developer D $533 \mathrm{~S}$ reacts with silver and is thus unusable for our purposes. For the AZ 5214E resist, the lithography process was without problems when the commercial developer AZ 726 MIF was used.
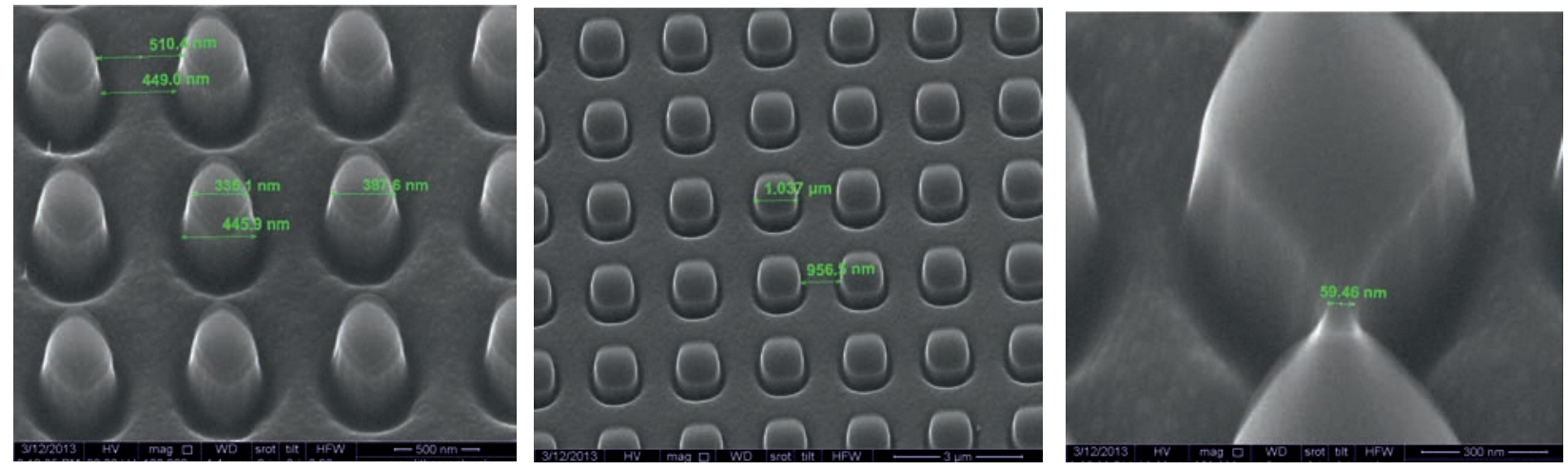

Fig. 4. SEM pictures of patterns achieved with the AZ 5214E, used at the same time as an etch mask for etching $\mathrm{GaAs}_{\mathrm{An}} \mathrm{SiCl}_{4}$ plasma. Left: an array of dots $(450 / 450 \mathrm{~nm})$; middle: an array of dots $(1 / 1 \mu \mathrm{m})$; right: detail of a $60 \mathrm{~nm}$ narrow motive created by this process. 
Table 2. RIE parameters for PMMA/Ag layers in $\mathrm{N}_{2}$ plasma

\begin{tabular}{ccccccc}
\hline $\begin{array}{c}\text { RF power } \\
(\mathrm{W})\end{array}$ & $\begin{array}{c}\text { etch time } \\
(\mathrm{min})\end{array}$ & \multicolumn{2}{c}{$\Delta(\mathrm{nm})$} & \multicolumn{2}{c}{ ER $(\mathrm{nm} / \mathrm{min})$} & ERPMMA/Ag \\
& PMMA & $\mathrm{Ag}$ & PMMA & $\mathrm{Ag}$ & $(\mathrm{nm} / \mathrm{min})$ \\
\hline 100 & 10 & 143 & 15 & 14.3 & 1.5 & 9.5 \\
150 & 10 & 345 & 26 & 34.5 & 2.6 & 13.2 \\
150 & 6 & 121 & 17 & 20.1 & 2.8 & 7.2 \\
300 & 6 & $>1000$ & 44 & $>166.6$ & 7.3 & $>23$ \\
300 & 3 & 600 & 15 & 200 & 5 & 40 \\
\hline
\end{tabular}

\section{RESULTS AND DISCUSSION}

\section{AZ 5214E used in EBDW and as an etch mask in $\mathrm{SiCl}_{4}$ plasma}

Figure 4 shows patterns on GaAs wafers exposed in the AZ 5214E resist by EBDW, followed by the RIE process with the resist used as a masking layer. To prevent resist charging during the e-beam exposure, the samples were covered by a thin layer of chromium $(12 \mathrm{~nm})$, which was subsequently removed by standard wet chemical etching.

SEM pictures of patterns were achieved with the AZ 5214E, used at the same time as an etch mask for etching $\mathrm{GaAs}$ in $\mathrm{SiCl}_{4}$ plasma. Left: an array of dots (450/450 nm); middle: an array of dots $(1 / 1 \mu \mathrm{m})$; right: detail of a $60 \mathrm{~nm}$ narrow motive created by this process.

An array of $450 / 450 \mathrm{~nm}$ dots is shown (Fig. 4) with visible layer of masking AZ 5214E on top of the structures (removed in later step). To achieve this profile three different exposure doses were used, after the exposure of the patterns the samples were descummed in $\mathrm{O}_{2}$ plasma ( $150 \mathrm{~W}, 1 \mathrm{~Pa}, 30 \mathrm{~s}$ ) and subsequently RIE etched in $\mathrm{SiCl}_{4}$ plasma ( $\left.40 \mathrm{~W}, 2 \mathrm{~Pa}, 3 \mathrm{~min}\right)$. A rather good homogeneity of the dots across the wafer was achieved; however an effect of trenching can be seen in the neighbourhood of the etched patterns. Due to a good resistance of the AZ $5214 \mathrm{E}$ resist to $\mathrm{SiCl}_{4}$ etching, we exposed the samples to another etching in oxygen plasma in order to decrease the resist thickness and its opening.

\section{RIE of Ag layers through the PMMA}

With regard to a high resolution of PMMA (better than that of the examined AZ 5214) we have decided to try this resist in N2 plasma despite the fact of its high E.R. value (Fig. 3; Tab. 1). We have etched the PMMA (deposited on $\mathrm{Ag}$ layers) at different $\mathrm{RF}$ power (1 $\mathrm{Pa}$; $20 \mathrm{sccm})$.

As can be seen in Table 2, optimal etching of Ag layers was achieved at RF power of $150 \mathrm{~W}$ and with the etchtime of 17 minutes (divided into 3 etch-cycles). For longer etch times increases also the etch rate for the PMMA. In order to eliminate the high E.R. of PMMA, we have also used an a:Si layer as a mask for $\mathrm{N}_{2}$ RIE plasma and we have observed (also in the case of other examined resists) some silver residuals redeposited on the a:Si surface that emerge at the contours of the structures. The structure of Ag layers on its surface as well as in cross-section was examined in SEM and the size of the grains was measured to be in the range of 30 to $300 \mathrm{~nm}$.

\section{RIE of Ag layers through the AZ 5214E}

We used standard lithography process for the AZ $5214 \mathrm{E}$ with the AZ $726 \mathrm{MIF}$ developer. The samples were RIE-etched in $\mathrm{N}_{2}$ plasma $(p=1 \mathrm{~Pa} ; P=500 \mathrm{~W}$; $\left.U_{S B}=-310 \mathrm{~V} ; t=4 \mathrm{~min}\right)$. However, the results of the etching showed also that there were residuals at the bottom of the etched structures. We have succesfully removed these residuals in $\mathrm{O}_{2}$ plasma $(1 \mathrm{~Pa}, 300 \mathrm{~W},-220 \mathrm{~V}$, $4 \mathrm{~min}$ ) but the silver surface oxidized (blue surface). Further etching in $\mathrm{O}_{2}$ plasma led to increasing the $\mathrm{Ag}$ layer (brownish colour); finally, in subsequent $\mathrm{N}_{2}$ plasma also the Ag oxide was etched away.

\section{CONCLUSIONS}

We have described an EBDW lithography process for the AZ 5214E photoresist which was used in imagereversal mode for its good properties for lift-off. Besides its rather good e-beam patternig use, this resist has shown to be interesting also for its resistance towards etching in $\mathrm{N}_{2}$ plasma (to etch thin Ag layers) but also in other plasmas $\left(\mathrm{SiCl}_{4}, \mathrm{CCl}_{4}\right.$ and $\left.\mathrm{SF}_{6}\right)$. An array of $450 / 450 \mathrm{~nm}$ dots of a good homogeneity across the wafer was achieved by a technique described in the article.

The experiments showed that for our e-beam lithography patterning purposes, PMMA is still a good candidate despite the fact that it has the highest etch-rate resistance of all the examined resists. Among other candidates with better plasma resistance, SU-8 and AZ 5214E are rather suitable, however formation of Ag residuals during RIE was observed which are not easy to be removed. In order to use better patterning advantages of PMMA and the above mentioned advantages of AZ 5214E, we have sputtered on the surface of $\mathrm{Ag}$ (via metallic mask) a thin a:Si layer that served as a mask for RIE etching in $\mathrm{N}_{2}$ plasma. The resistance the a:Si masking layer in $\mathrm{N}_{2}$ plasma was very good and an 80nm-thick masking layer was sufficient for etching a $48 \mathrm{~nm}$-thick Ag layer. To remove the a:Si masking layer, we have tried $\mathrm{SF}_{6}$ plasma which turned to be unsuitable due to the fact that sulphur reacts with silver by degrading it. That is why to remove the a:Si 
layer, $\mathrm{CF}_{4}$ was used instead as etching gas. The elimination of undesirable $\mathrm{Ag}$ clusters after $\mathrm{N}_{2}$ RIE will be object of our future investigations.

\section{Acknowledgements}

The authors would like to thank V. Barák, A. Ritomský and I. Čaplovič for technical assistance in e-beam lithography, and $\breve{S}$. Haščík for the RIE etching in $\mathrm{SiCl}_{4}$ plasma. SEM examination was made by Inspect F50 (FEI) at ElU SAV, Bratislava. This work was supported by the Scientific Grant Agency of the Ministry of Education of the Slovak Republic, the Slovak Academy of Sciences No. VEGA- 2/0021/12 and 1/0439/13, and the APVV projects No. 0450-10 and 0037-10.

\section{REFERENCES}

[1] Clariant Product Datasheet for the AZ 5214E photoresist.

[2] ELIÁŠ, P.—GREGUŠOVÁ, D.-MARTAUS, J.—KOSTIČ, I. : Conformal AZ5214-E Resist Deposition on Patterned (100) InP Substrates, Journal of Micromechanics and Microengineering 16 (2006), 191-197.

[3] ELIÁŠ, P.-GREGUŠOVÁ, D.-STRICHOVANEC, P.—KOSTIČ, I.-NOVÁK, J. : Deposition of AZ5214-E Layers on Nonplanar Substrates with a "Draping" Technique, Proc. of. Advanced Semiconductor Devices and Microsystems (ASDAM) (2006), 97-100.

[4] LIU, HUA-YU- LIU, E. D.: Diffusion in AZ-5214 Image Reversal Process and its Application to e-Beam Proximity Effect Correction, Microelectronic Engineering 6 (1987), 439-446.

[5] SPAK, M.-MAMMATO, D.-JAIN, S.-DURHAM, D. : Mechanism and Lithographic Evaluation of Image Reversal in AZ 5214 Photoresist, AZ Electronic Material 7 (2000), 16-23.

[6] HOVINEN, A.-MALININ, A.-LIPSANEN, A.: Lithography in Experimental Environment, Reports in Electron Physics 2000/21, Helsinki University of Technology, Helsinki, 2000.

[7] ELIÁŠ, P.-STRICHOVANEC, P.-KOSTIČ, I.-NOVÁK, J. : Conformal, Planarizing and Bridging AZ5214-E Layers Deposited by a 'Draping' Technique on Non-Planar III-V Substrates, Journal of Micromechanics and Microengineering 16 (2006), 2608-2617.

[8] MURAKOWSKI, J.-SCHNEIDER, G.-PRATHER, D. W. : Combination Lithography for Photonic Crystal Circuits, SPIE 5000 (2003), 43-50.

[9] Dunboddin, D. R.-FAguet, J.: Single Step, Positive Tone Lift-Off Process Using AZ 5214-E Resist, SPIE 922 (1988), 247-254.

[10] BALACHOVA, O. V.-ALVES, M. A. R.-SWART, J. W.BRAGA, S.-CESCATO, L.: CF4 Plasma Etching of Materials Used in Microelectronics Manufacturing, Microelectronics Journal 31 (2000), 213-215.
[11] TAE-SEOP CHOI et al: ECS Journal of Solid State Science and Techn. 2 No. 6, 275-281.

[12] LEE, YOUNG-JOON et al: Japanese Journal of Applied Physics 42 No. 1 (2003), 286.

[13] NAKATANI, I.: Dry Etching, US patent No. 6878635 B1.

Received 15 April 2013

Robert Andok (Ing, Mgr, $\mathrm{PhD}$ ) received his $\mathrm{PhD}$ degree in Microelectronics from the Slovak University of Technology in Bratislava in 2001. At present he works at the Institute of Informatics, Slovak Academy of Sciences in Bratislava. Main interests of his research include micro- and nanotechnology, MEMS, and electron-beam lithography.

Anna Benčurová (Ing) received her Ing degree from the Slovak University of Technology, Bratislava, in 1989. At present she works at the Institute of Informatics, Slovak Academy of Sciences in Bratislava. Her main research interests include electron-beam lithography, micro- and nanotechnology and CAD data preparation.

Pavol Hrkút (Ing, CSc) received his CSc degree in Microelectronics from the Slovak Academy of Sciences in Bratislava in 1987. At present he works at the Institute of Informatics, Slovak Academy of Sciences in Bratislava. Main interests of his research include micro- and nanotechnology, MEMS, and electron-beam lithography. He is the holder of the US patent No. 6.136.160, Oct. 2000.

Anna Konečníková (Ing) received her Ing degree from the Slovak University of Technology, Bratislava, in 1979. At present she works at the Institute of Informatics, Slovak Academy of Sciences in Bratislava. Her main research interests include electron-beam lithography and technological processes during the materials preparation for the e-beam lithography.

Ladislav Matay (Ing, $\mathrm{PhD}$ ) received his $\mathrm{PhD}$ degree in Microelectronics from the Slovak University of Technology in Bratislava in 2005. At present he works at the Institute of Informatics, Slovak Academy of Sciences in Bratislava. Main interests of his research include micro- and nanotechnology, MEMS, and NMES, specifically PVD deposition of thin films.

Pavol Nemec (Ing) received his Ing degree from the Slovak University of Technology in Bratislava in 2000. At present he works at the Institute of Informatics, Slovak Academy of Sciences in Bratislava. His main research interests include micro- and nanotechnology, data preparation and characterization in electron-beam lithography.

Jaroslava Škriniarová (Ing, CSc) received her Ing. (MSc) and CSc degree from the Slovak University of Technology (STU), Bratislava, in 1977 and 1986. In 1993 she joined the Microelectronics Department of STU, at present she is there engaged in the research of optoelectronic devices. Her scientific interests include chemical processing of semiconductor materials, thin films and surfaces. 